\title{
Ensino de Física para pessoas com deficiência visual: análise de trabalhos apresentados em eventos científicos brasileiros entre 2013 e 2017
}

\author{
Physics teaching for visually impaired people: analysis of studies \\ presented at Brazilian scientific events from 2013 to 2017
}

\author{
Maxiwilian Sant'Ana Polverini ${ }^{1}$ (i); Estéfano Vizconde Veraszto ${ }^{1}$ (i); \\ José Tarcísio Franco de Camargo ${ }^{2}$ (i); Brena Santana Zanzarini Nahum ${ }^{1}$ (1) \\ ${ }^{1}$ Universidade Federal de São Carlos (UFSCar). ${ }^{2}$ Centro Regional Universitário de \\ Espírito Santo do Pinhal (UNIPINHAL), Brasil
}

\begin{abstract}
Resumo
Este trabalho apresenta um estudo na área de Ensino de Física e Educação Especial, tendo como foco o ensino de Física para pessoas com deficiência visual. O estudo teve como objetivo identificar, do ponto de vista didático, se os artigos científicos apresentados nos últimos cinco anos nos eventos científicos brasileiros de Ensino de Física (EPEF e SNEF) e de Ensino de Ciências (ENPEC) estão de acordo com uma educação verdadeiramente inclusiva. Para atender esse objetivo, foi realizada uma pesquisa bibliográfica nas atas e nos anais dos eventos, disponíveis on-line, utilizando como técnica de análise dos dados a Análise de Conteúdo, mediante uma abordagem qualitativa. Os resultados indicaram um valor muito abaixo do esperado comparado à quantidade de trabalhos analisados. Concluímos que estudantes de licenciatura, professores da educação básica e pesquisadores no Ensino de Física devem rever suas práticas de ensino de modo a desenvolverem uma atividade educacional legitimamente inclusiva.
\end{abstract}

Palavras-chave: ensino de física; educação especial; educação inclusiva; deficiência visual; eventos científicos.

\begin{abstract}
This paper presents a study in the area of Physics Teaching and Special Education, focusing on Physics teaching for visually impaired people. The study aimed to identify, from a didactic point of view, if the scientific articles presented in the last five years in the Brazilian scientific events of Physics Teaching (EPEF and SNEF) and Science Teaching (ENPEC) are in agreement with a truly inclusive education. To achieve this goal, a bibliographic research was made in the proceedings of the events, available online, using as data analysis method the Content Analysis technique, through a qualitative approach. The results indicated a value much lower than expected compared to the amount of studies analyzed. We conclude that undergraduate students, primary school teachers and researchers in physics education should review their teaching practices in order to develop a real inclusive educational activity.
\end{abstract}

Keywords: physics teaching; special education; inclusive education; visual disability; scientific events.

Como citar (APA):

Polverini, M., Veraszto, E., Franco de Camargo, J. T. \& Nahum, B. (2021). Ensino de Física para pessoas com deficiência visual: análise de trabalhos apresentados em eventos científicos brasileiros entre 2013 e 2017. Revista Iberoamericana de Educación, 85(2),95-118. https://doi.org/10.35362/rie8523794 


\section{Introdução}

O Censo Escolar de 2017 aponta um aumento substancial de matrículas na educação básica de alunos, entre de 4 a 17 anos, com deficiência, transtornos globais do desenvolvimento ou altas habilidades. Do mesmo modo, foi constatado aumento de matrículas de alunos com necessidades educacionais especiais (NEE) dessa faixa etária, passando de 85,5\%, em 2013, para 90,9\%, em 2017. Além disso, o acesso ao atendimento educacional especializado (AEE) também aumentou de 35,2\%, em 2013, para 40,1\%, em 2017. Em contrapartida, o ensino especial (segregado) diminuiu de $14,5 \%$, em 2013, para 9,1\%, em 2017. (Brasil, 2017).

Além disso, também podemos citar o Censo Demográfico de 2010, realizado pelo Instituto Brasileiro de Geografia e Estatística (IBGE), o qual indica que 23,9\% da população brasileira possui algum tipo de deficiência, ou seja 45,6 milhões de pessoas ${ }^{1}$. Das modalidades de deficiência recenseadas (visual, auditiva, motora e mental ou intelectual) a deficiência visual (DV) apresentou a maior ocorrência, afetando $18,8 \%$ da população brasileira (Oliveira, 2012). O IBGE considerou três graus de severidade, mediante a dificuldade permanente de enxergar: não consegue de modo algum $(0,3 \%)$, grande dificuldade (3,2\%) e alguma dificuldade (15,3\%) (Andrés, 2014). São dados confiáveis, que mostram a dimensão da DV no país, mas não apontam, com exatidão, quantos desses indivíduos estão em idade escolar, e quais, em idade escolar, estão matriculados na educação básica ou superior.

De forma paralela a essa realidade, é sabido que há algum tempo a perda de interesse dos discentes pelas disciplinas de caráter científico tem preocupado professores e influenciado pesquisas acadêmicas no Brasil e ao redor do mundo (Carvalho \& Sasseron, 2018; Carvalho \& Gil-Pérez, 2011; Yamazaki, Angotti \& Delizoicov, 2017). É nesse âmbito que os primeiros desafios do ensino de física se apresentam. A falta de motivação para se estudar conteúdos de física parece aumentar na medida que o aluno adentra o Ensino Médio. Muito provavelmente esse fato está atrelado à criação de paradigmas e preconceitos que têm se perpetuado ao longo do tempo. Por outro lado, também é preciso considerar que muitas vezes essa falta de motivação, que chega à rejeição, é fruto de um trabalho que vem sendo

\footnotetext{
${ }^{1}$ A população total registrada em 2010 foi de "190.732.694 pessoas." (Andrés, 2014, p. 7). Hoje, a população total corresponde à 209.024.499 pessoas (IBGE, 2018). Disponível em https://www.ibge.gov.br/apps/populacao/projecao.
} 
desenvolvido há décadas dentro da sala de aula, onde a física (e as demais ciências da natureza) é tratada de forma alheia à realidade do aluno (Gil-Pérez \& Vilches, 2005).

Assim, temos consciência que ensinar física não é tarefa fácil. $E$, dentro desse contexto, ensinar física para o estudante com DV torna-se ainda mais desafiador, já que, além das costumeiras dificuldades, esse aluno geralmente se depara com conteúdos transmitidos a partir de forte apelo visual. Na busca por representar conceitos e fenômenos, seja a partir do uso de giz, lousa, recursos digitais ou livros didáticos, docentes buscam apoio em gráficos, diagramas, símbolos, fórmulas matemáticas, desenhos, imagens, entre outros, que são inacessíveis para o aluno com DV (Camargo, 2012; Veraszto, Camargo, Camargo, Simon \& Miranda, 2018a; Veraszto, Camargo, Camargo, Simon, Yamaguti \& Souza, 2018b).

Além disso, também podemos apontar que as interações dos(as) professores(as) com os(as) alunos(as) com NEE e/ou deficiência se ampliaram por meio da inclusão, o que pode originar as chamadas barreiras atitudinais (Amaral, 2002). Estas barreiras podem estar presentes tanto nos professores quanto na comunidade escolar, favorecendo dificuldades para o processo de ensino e aprendizagem desses alunos e podendo afetar a prática pedagógica do(a) professor(a) sobre a inclusão.

Assim, dentro desse panorama brevemente descrito, a presente pesquisa se configurou a partir de um misto de preocupação e interesse em averiguar como estudos recentes têm proposto o ensino dos conteúdos da disciplina para pessoas com DV, uma vez que a presença desses na sala de aula comum do ensino regular cresce a cada ano. Desta forma, tomando como base artigos científicos publicados nos eventos científicos nacionais de Ensino de Física (EPEF e SNEF) e de Ensino de Ciências (ENPEC), no período compreendido entre 2013-2017, esta pesquisa se propõe a identificar como os trabalhos tratam o Ensino de Física para pessoas com DV em uma perspectiva realmente inclusiva, tomando como ponto de partida artigos que desenvolvem e/ou aplicam propostas para diferentes processos de ensino-aprendizagem. 


\section{Desenvolvimento teórico}

Incialmente é importante enfatizar que existem categorias que conceituam a DV e, diferentemente do que supõe o senso comum, o termo em si não se restringe somente às pessoas cegas. De acordo com o Decreto 5.296 (Brasil, 2004), duas categorias são estabelecidas: os cegos e os que possuem baixa visão. Assim, cega é a pessoa cuja acuidade visual, no melhor olho, e com a melhor correção óptica, é menor que 20/400 (0,05), ou seja, essa pessoa vê a $20 \mathrm{~m}$ aquilo que uma pessoa de visão comum veria à $400 \mathrm{~m}$ de distância. Desta maneira, pessoas com acuidade visual menor que a citada, são consideradas cegas mesmo que sejam capazes de ver vultos ou resquícios de imagem. É considerado com baixa visão todo indivíduo cuja acuidade visual, no melhor olho, e com a melhor correção óptica, é menor que $20 / 70(0,3)$ e maior que $20 / 400(0,05)$, ou ainda, os casos onde a somatória da medida do campo visual em ambos os olhos for igual ou menor que $60^{\circ}$, ou a ocorrência simultânea de quaisquer das condições anteriores (Camargo, 2012, 2016a, 2016b). Além disso, diferentes tipos de DV, abordadas do ponto de vista do diagnóstico clínico, sinalizam a presença de algum elemento patogênico no organismo.

Não obstante, a DV é um fenômeno mais complexo e não pode ser simplesmente atribuída a uma característica inerente ao indivíduo. Condições de desvantagem e limitações de pessoas com DV em contextos sociais, como o educacional, não devem ser entendidas como decorrentes exclusivamente de fatores físicos. A desvantagem só existe a partir do momento que os atributos prejudicados são tidos como prioritários para interação do indivíduo como o meio social (Camargo, 2016a; Omote, 1986; Veraszto et al., 2018a).

Assim, a DV deve ser entendida como algo a mais do que um déficit orgânico sensorial. ADV é também um fenômeno social, pois implica em determinadas formas inadequadas de perceber, agir e pensar frente a deficiência, gerando julgamentos, atitudes e preconceitos que refratam negativamente o modo de vida dessas pessoas, em vários contextos e diferentes espaços. Esse prejulgamento cultural, gerido pela sociedade vidente, vinculado a valores e crenças, desenvolve práticas sociais inadequadas que dificultam o indivíduo com DV a realizar tarefas comuns e cotidianas (Camargo, 2008, 2016a; Vigotski, 1997; Nuernberg, 2008; Veraszto, Camargo, Camargo, Simon, Yamaguti \& Souza, 2018). 


\subsection{Educação inclusiva: a escola para todos}

A educação inclusiva, considerando discentes com NEE, atravessou um longo percurso até a garantia atual do direito a uma educação equânime. De forma resumida, podemos apontar que mudanças começaram a ser delineadas a partir da promulgação da Constituição Federal, em 1988, ao estabelecer no Art. 206, Inciso I, igualdade de condições para o acesso e permanência na escola (Brasil, 1988) e no Art. 208, Inciso III, atendimento educacional especializado aos portadores de deficiência, preferencialmente na rede regular de ensino (Brasil, 1988). Além disso, foi também com o artigo 58 da LDB, que a educação escolar de educandos com deficiência começou a ter oferta prevista, preferencialmente, no ensino regular (Brasil, 1996). Assim, o foco da atmendonenção não deveria mais recair isoladamente no aluno (e suas peculiaridades), mas também em todo o ambiente que o envolve (Mendes, 2006). Nesta perspectiva, começou a ser traçada a ideia de que a educação inclusiva deveria oferecer um modelo de ensino para congregar todos os estudantes, com e sem NEE, no contexto escolar, mediante a construção de uma abordagem pedagógica consciente da diversidade humana, tendo a diferença como ponto de partida (Camargo, 2008, 2012). Essa mudança de perspectiva educacional implica em substituir o conceito de igualdade (ou homogeneização), pelo conceito de equidade. Em linhas gerais, a igualdade trata todo mundo igual. E nem todos são iguais. $\mathrm{E}$, a equidade, prima por um tratamento justo e imparcial, considerando as particularidades e necessidades de cada caso.

\subsection{Autonomia}

Aeducação tem a função primordial de emancipação do homem para a prática da condição humana, de modo a determinar plenamente sua própria vida, considerando as estruturas sociais nas quais está inserido. Essa característica deve se destinar a alunos com ou sem DV, garantindo a liberdade do pensamento, na medida que leva a pessoa a conceber, fantasiar, imaginar, decidir e à capacidade de realizar alguma ação livremente (Zatti, 2007). Nessa perspectiva, a atividade educacional precisa estimular e/ou favorecer o estudante com ou sem DV a ter posicionamentos independentes, favorecendo o pensamento e ação individual, quando necessário, proporcionando condições para o desenvolvimento do senso crítico. 


\subsection{Comunicação interpessoal}

Em um processo de comunicação interpessoal, ocorre uma relação entre o emissor e o receptor, na qual o primeiro veicula intencionalmente uma mensagem para o segundo, com a finalidade de compartilhar significados sobre determinado objetivo, informação, ideia ou mensagem. Neste sentido, a comunicação representa o fator essencial para que a inclusão ocorra de forma efetiva, garantindo participação do aluno DV (Camargo, Nardi \& Correia, 2010; Camargo, 2012, 2016). Deste modo, atividades educacionais devem priorizar contextos comunicacionais que favoreçam a interação entre alunos com DV, videntes e professor, de modo a intercalar momentos de discussão e exposição de ideias entre os participantes, com momentos de apresentação das ideias aceitas cientificamente (realizada pelo professor).

\subsection{Multisensorialidade}

Uma das principais formas que possibilita diminuir barreiras comunicacionais de pessoas com DV é a utilização do Sistema Braille (ou Código Braille). Trata-se do recurso destinado à leitura e escrita em relevo mais adotado no mundo, sendo composto também por representações dos símbolos matemáticos, químicos, musicais, etc. (Brasil, 2002). Contudo, apesar da sua relevância, nem todas as pessoas com DV o utilizam, seja pela impossibilidade de desenvolver a habilidade tátil essencial para esse tipo de leitura, ou porque não possuem essa capacidade em decorrência de problemas de saúde nas mãos. Assim, para que as diferenças entre todas as pessoas sejam respeitadas e o acesso à informação garantido, a adoção de recursos multissensoriais, concomitante com contextos comunicacionais adequados, pode ser uma alternativa promissora (Torres, Mazzoni \& Mello, 2007).

\section{Metodologia}

Este trabalho, de abordagem qualitativa, utiliza pressupostos de pesquisa exploratória e bibliográfica. Como pesquisa exploratória, não encontrando precedentes, mapeou trabalhos destinados ao ensino de física para alunos com DV, explorando o objetivo original. Assim, buscamos compreender os vários aspectos do fenômeno estudado com o intuito de tornar o problema mais familiar e descritivo, uma vez que se descreveram as características de dada população ou fenômeno (Richardson, Peres, Wanderley, Correia \& Peres, 2012; Gil, 2017). Também se configura como pesquisa bibliográfica, 
considerando que delineou o estado da arte da temática estudada, dentro de período temporal especificado (Marconi \& Lakatos, 2017). Neste sentido, com o intuito buscar melhor entendimento da produção atual acerca do ensino de Física para DV em caráter nacional, optou-se por analisar os trabalhos apresentados em eventos científicos nacionais de Ensino de Física e de Ensino de Ciências, no período compreendido entre 2013-2017.

A escolha dos eventos foi feita, considerando que os mesmos refletem tendências atuais de pesquisa na área. Assim, os trabalhos analisados foram selecionados a partir dos anais, disponíveis em formato online, dos seguintes eventos: as edições de 2014 e 2016 do Encontro de Pesquisa em Ensino de Física (XV EPEF e XVI EPEF)2; as edições de 2013, 2015 e 2017 do Simpósio Nacional de Ensino de Física (XX SNEF, XXI SNEF e XXII SNEF) e as edições de 2013, 2015 e 2017 do Encontro Nacional de Pesquisa em Educação em Ciências (IX ENPEC, X ENPEC XI ENPEC).

Os levantamentos foram realizados manualmente, sem utilização de campos de busca, de modo a não restringir a pesquisa somente pela utilização de palavras-chaves pré-determinadas. No processo, buscou-se uma aproximação do tema em estudo: artigos com títulos que se afastavam da proposta da pesquisa foram prontamente descartados. Contudo, houve a preocupação em verificar a clareza dos demais, a partir de leitura inicial do resumo e das palavras-chaves. A partir dessa triagem inicial, foram separados 74 artigos (tabela 1 ).

Tabela 1. Trabalhos encontrados dentro da temática.

\begin{tabular}{llllllllll}
\hline \multicolumn{1}{c}{ Evento } & \multicolumn{2}{c}{ EPEF } & \multicolumn{3}{c}{ SNEF } & \multicolumn{3}{c}{ ENPEC } \\
Ano & 2014 & 2016 & 2013 & 2015 & 2017 & 2013 & 2015 & 2017 \\
N $^{0}$ de trabalhos & 4 & 3 & 10 & 8 & 22 & 8 & 11 & 8 \\
\hline
\end{tabular}

Fonte: elaborado pelos autores.

Foram utilizadas técnicas de Análise de Conteúdo (Bardin, 2011) para análise dos artigos. O procedimento de análise foi dividido em:

- Organização da Análise: a partir: [a] pré-análise, com leitura flutuante e organização do material constituído, para início do processo de

\footnotetext{
${ }^{2}$ A edição referente ao ano de 2018 (XVII) não entrou na elaboração deste trabalho, considerando que o mesmo estava em fase de finalização em período concomitante com a realização do evento.
} 
categorização; [b] exploração do material, sistematizando as decisões tomadas, [c] tratamento dos resultados e interpretação, buscando relações e agrupamentos por semelhanças.

- Codificação: tratamento do material a partir da fundamentação teórica, buscando a transformação dos dados brutos, segundo escolhas das unidades, que auxiliaram agregar as informações, enumerando-as a partir de regras de contagem.

- Categorização: realização da classificação final dos dados por diferenciação e agrupamento em torno de critérios previamente estabelecidos (categorias emergentes da fundamentação teórica, no caso deste trabalho (Bardin, 2011).

- Inferência e interpretação: onde foram apresentadas as discussões relativas às categorias constituídas.

\section{Análise dos dados}

Após a leitura dos artigos científicos foi constatado que vários trabalhos abordavam diferentes processos de ensino-aprendizagem de Física para alunos com DV: concepções espontâneas de licenciandos, situações enfrentadas por licenciandos com DV na universidade; investigações baseadas em conferir a qualidade das escolas e professores diante da realidade da educação inclusiva de alunos com DV. Considerando essa diversidade dentro da mesma temática, a delimitação da análise centrou esforços em trabalhos relacionados especificamente com o ensino. Assim, o corpus da pesquisa foi formado por 38 trabalhos, distribuídos conforme tabela 2.

Tabela 2. Corpus da pesquisa.

\begin{tabular}{lllllllll}
\hline \multicolumn{1}{c}{ Evento } & \multicolumn{2}{c}{ EPEF } & \multicolumn{3}{c}{ SNEF } & \multicolumn{3}{c}{ ENPEC } \\
Ano & 2014 & 2016 & 2013 & 2015 & 2017 & 2013 & 2015 & 2017 \\
Trabalhos selecionados & 2 & 0 & 9 & 5 & 11 & 3 & 4 & 4 \\
\hline
\end{tabular}

Fonte: elaborado pelos autores.

Após definido o corpus da pesquisa, para viabilizar a escrita dos resultados e análise, os trabalhos foram classificados da seguinte forma: nomearam-se os artigos com a primeira inicial do nome do evento científico (com exceção do EPEF, onde foram usadas as duas letras iniciais) com o respectivo ano de ocorrência na sequência. Exemplo: um artigo apresentado no SNEF de 2013 ficou classificado como S13. Para diferenciar os artigos em um mesmo 
evento de determinado ano, utilizaram-se os numerais cardinais (S13-1, S13-2, S13-3, etc.). A tabela 3 apresenta a classificação dos artigos, suprimindo a autoria.

Tabela 3. Classificação dos artigos.

\begin{tabular}{lll}
\hline Evento & \multicolumn{1}{c}{$N$} & \\
\hline EPEF & EP14-1 & $\begin{array}{l}\text { Experimento com realidade virtual e aumentada e o ensino de } \\
\text { física para alunos com pouca ou nenhuma visão }\end{array}$ \\
SNEF & EP14-2 & $\begin{array}{l}\text { Neurociência cognitiva no processo de aprendizagem de } \\
\text { alunos com deficiência visual: desenvolvimento de experimento } \\
\text { com fluidos para o ensino de física }\end{array}$ \\
& Material didático para o ensino de física inclusivo: exemplo de \\
uma sequência didática para a abordagem de conceitos da & eletrodinâmica
\end{tabular}




\begin{tabular}{|c|c|c|}
\hline Evento & $\mathrm{N}$ & Título do artigo \\
\hline \multirow[t]{11}{*}{$\begin{array}{l}\text { SNEF } \\
2017\end{array}$} & S17-1 & $\begin{array}{l}\text { Propostas de atividades de cinemática para deficientes visuais } \\
\text { aplicada no colégio pedro ii pelo grupo do pibid/ufrj - fisica }\end{array}$ \\
\hline & S17-2 & $\begin{array}{l}\text { Conceituação de equilíbrio estático utilizando maquete tátil- } \\
\text { visual }\end{array}$ \\
\hline & S17-3 & Vivendo num mundo sem luz \\
\hline & S17-4 & $\begin{array}{l}\text { Construção de maquetes no contexto da deficiência visual: } \\
\text { possibilidade para o ensino de temas de astronomia no ensino } \\
\text { fundamental ii }\end{array}$ \\
\hline & S17-5 & $\begin{array}{l}\text { Espaços não formais de aprendizado e o ensino de física para } \\
\text { alunos com baixa visão ou cegueira }\end{array}$ \\
\hline & S17-6 & $\begin{array}{l}\text { Desenvolvimento e aplicação de uma maquete sobre as leis } \\
\text { de Kepler para inclusão de alunos com deficiência visual no } \\
\text { ensino de física }\end{array}$ \\
\hline & S17-7 & $\begin{array}{l}\text { Uso da audiodescrição como uma ferramenta de ensino no } \\
\text { ensino de ciências exatas }\end{array}$ \\
\hline & S17-8 & $\begin{array}{l}\text { Lei de hooke: uma proposta de ação pedagógica para } \\
\text { a inclusão educacional de alunos com necessidades } \\
\text { educacionais especiais visuais }\end{array}$ \\
\hline & S17-9 & $\begin{array}{l}\text { Ensino de ondas para estudantes com e sem deficiência } \\
\text { visual da Educação de Jovens e Adultos - EJA - com materiais } \\
\text { concretos e de baixo custo. }\end{array}$ \\
\hline & S17-10 & $\begin{array}{l}\text { Inscrições didáticas adaptadas para estudantes cegos: } \\
\text { exemplo em uma unidade didática de circuitos elétricos }\end{array}$ \\
\hline & S17-11 & Acessibilidade no ensino de física \\
\hline \multirow[t]{3}{*}{$\begin{array}{l}\text { ENPEC } \\
2013\end{array}$} & E13-1 & $\begin{array}{l}\text { Formação de professores de Física inclusivistas: } \\
\text { interdisciplinaridade por si... }\end{array}$ \\
\hline & E13-2 & $\begin{array}{l}\text { Representação de diagramas do livro didático de física: Uma } \\
\text { Proposta para a Melhoria da Autonomia de Estudantes com } \\
\text { Deficiência Visual }\end{array}$ \\
\hline & E13-3 & $\begin{array}{l}\text { Linguagem latex vs. Linguagem matemática convencional - } \\
\text { Diminuindo barreiras para o acesso de alunos com deficiência } \\
\text { visual a textos de Ensino de Física por meio do computador }\end{array}$ \\
\hline \multirow[t]{4}{*}{$\begin{array}{l}\text { ENPEC } \\
2015\end{array}$} & $\mathrm{E} 15-1$ & $\begin{array}{l}\text { Acessibilidade para estudantes cegos e baixa visão: uma } \\
\text { análise dos objetos educacionais digitais do Programa } \\
\text { Nacional do Livro Didático de Física }\end{array}$ \\
\hline & E15-2 & $\begin{array}{l}\text { Proposta de construção de uma aula inclusiva de Física sobre } \\
\text { o tema Energia }\end{array}$ \\
\hline & E15-3 & $\begin{array}{l}\text { A experimentação com cegos e videntes nos anos iniciais do } \\
\text { ensino fundamental }\end{array}$ \\
\hline & E15-4 & $\begin{array}{l}\text { Diversificação Sensorial nas Aulas de Física em Escolas } \\
\text { Regulares: Planejamento de Atividades Para Todos os Alunos }\end{array}$ \\
\hline
\end{tabular}




\begin{tabular}{|c|c|c|}
\hline Evento & $\mathrm{N}$ & Título do artigo \\
\hline ENPEC & $\mathrm{E} 17-1$ & Formação inicial de professores de física inclusivistas \\
\hline \multirow[t]{3}{*}{2017} & $\mathrm{E} 17-2$ & $\begin{array}{l}\text { Concepções das pessoas com deficiência visual sobre a Lua } \\
\text { para produção de um material paradidático adaptado. }\end{array}$ \\
\hline & E17-3 & $\begin{array}{l}\text { Quando a cor é uma vibração em uma corda: buscando } \\
\text { invariantes operatórios utilizados por estudantes cegos na } \\
\text { interação com objetos físicos }\end{array}$ \\
\hline & E17-4 & $\begin{array}{l}\text { A elaboração de recursos didáticos para o ensino de } \\
\text { Astronomia para deficientes visuais }\end{array}$ \\
\hline
\end{tabular}

Fonte: elaborado pelos autores.

A partir da leitura minuciosa, os trabalhos foram organizados, classificados, ordenados e categorizados, mediante aproximação dos resultados com a fundamentação teórica, conforme descrito na metodologia. Todavia, como também já fora apontado, categorias e subcategorias nasceram da fundamentação teórica e foram organizadas segundo a tabela 4.

Tabela 4. Categorias e subcategorias de análise.

\begin{tabular}{llll}
\hline & \multicolumn{1}{c}{ Categoria } & & \multicolumn{1}{c}{ Subcategoria } \\
\hline C1 & $\begin{array}{l}\text { Participantes da Atividade } \\
\text { Educacional }\end{array}$ & C1.1 & Alunos são apenas alunos \\
& C1.2 & Alunos com deficiência visual \\
C2 & Participação Efetiva & C.2.1 & Autonomia \\
& & C.2.2 & $\begin{array}{l}\text { Interação social/Comunicação } \\
\text { interpessoal }\end{array}$ \\
& & C3.1 & Multissensoriais \\
C3 & Recursos de Acesso & C3.2 & Não visuais \\
\hline
\end{tabular}

Fonte: elaborado pelos autores.

Antes de prosseguir e apresentar resultados e discussões para cada categoria e subcategoria, é preciso apontar que os trabalhos analisados foram sintetizados de forma a oferecer uma visão geral de como a categorização se organizou. Dessa forma, nos antecedemos com o resumo do resultado da categorização, buscando mostrar a organização das pesquisas, por categorias, na tabela 5 . 
Tabela 5. Classificação dos artigos científicos no período de 2013-2017

\begin{tabular}{|c|c|c|c|c|}
\hline $\begin{array}{l}\text { Cate- } \\
\text { goria }\end{array}$ & $\begin{array}{c}\text { Subcate- } \\
\text { goria }\end{array}$ & EPEF & SNEF & ENPEC \\
\hline \multirow[t]{2}{*}{$\mathrm{C} 1$} & C1.1 & EP14-2 & $\begin{array}{l}\text { S13-3; S15-1; S15-3; S15-4; } \\
\text { S17-1; S17-2; S17-3; S17-4; } \\
\text { S17-7; S17-8; S17-9 }\end{array}$ & $\begin{array}{l}\text { E13-1; E15-1; } \\
\text { E15-2; E15-3; } \\
\text { E15-4; E17-1 }\end{array}$ \\
\hline & C1.2 & EP14-1 & $\begin{array}{l}\text { S13-1; S13-2; S13-4; S13-5; } \\
\text { S13-6; S13-7; S13-8; S13-9; } \\
\text { S15-2; S15-5; S17-5; S17-6; } \\
\text { S17-10; S17-11 }\end{array}$ & $\begin{array}{l}\text { E13-2; E13-3; } \\
\text { E17-2; E17-3; } \\
\text { E17-4 }\end{array}$ \\
\hline \multirow[t]{2}{*}{ C2 } & C.2.1 & $\begin{array}{l}\text { EP14-1; } \\
\text { EP14-2 }\end{array}$ & $\begin{array}{l}\text { S13-1; S13-2; S13-3; S13-4; } \\
\text { S13-6; S13-7; S13-8; S13-9; } \\
\text { S15-1; S15-2; S15-3; S15-4; } \\
\text { S15-5; S17-1; S17-2; S17-3; } \\
\text { S17-4; S17-5; S17-6; S17-7; } \\
\text { S17-8; S17-9; S17-10; S17-11 }\end{array}$ & $\begin{array}{l}\text { E13-2; E13-3; } \\
\text { E15-1; E15-2; } \\
\text { E15-3; E17-2; } \\
\text { E17-3; E17-4 }\end{array}$ \\
\hline & C.2.2 & $\begin{array}{l}\text { EP14-1; } \\
\text { EP14-2 }\end{array}$ & $\begin{array}{l}\text { S13-4; S13-6; S13-7; S13-8; } \\
\text { S15-1; S15-3; S15-4; S15-5; } \\
\text { S17-1; S17-5; S17-6; S17-7; } \\
\text { S17-8; S17-9 }\end{array}$ & $\begin{array}{l}\text { E13-2; E15-1; } \\
\text { E15-2; E15-3; } \\
\text { E17-2; E17-3 }\end{array}$ \\
\hline \multirow[t]{2}{*}{ C3 } & C3.1 & EP14-1 & $\begin{array}{l}\text { S13-1; S13-3; S13-4; S13-6; } \\
\text { S13-9; S15-1; S15-2; S15-4; } \\
\text { S17-1; S17-2; S17-3; S17-4; } \\
\text { S17-7; S17-8; S17-9 }\end{array}$ & $\begin{array}{l}\text { E13-1; E15-1; } \\
\text { E15-2; E15-3; } \\
\text { E15-4; E17-1; } \\
\text { E17-2; E17-3 }\end{array}$ \\
\hline & C3.2 & EP14-2 & $\begin{array}{l}\text { S13-2; S13-5; S13-7; S13-8; } \\
\text { S15-3; S15-5; S17-5; S17-6; } \\
\text { S17-10; S17-11 }\end{array}$ & $\begin{array}{l}\text { E13-2; E13-3; } \\
\text { E17-4 }\end{array}$ \\
\hline
\end{tabular}

Fonte: elaborado pelos autores.

Considerando essa distribuição, a explicitação que será apresentada na sequência mostra a relação íntima de cada categoria e subcategoria com o quadro teórico esboçado anteriormente.

\subsection{Participantes da atividade educacional}

Analisando os trabalhos, percebemos que, dos 38 artigos científicos que constituíram o corpus de pesquisa, 20 propuseram atividades apenas destinadas a alunos com DV. Assim, logo de início foi possível perceber que processos inclusivos não estavam presentes, de fato, nos artigos e respectivas propostas. Por isso, foi necessário dividir a categoria em 2 subcategorias construídas a partir dos perfis de alunos componentes da atividade educacional planejada e/ou aplicada em cada trabalho: Alunos são apenas alunos e Alunos com deficiência visual. 


\section{Alunos são apenas alunos}

Esta subcategoria foi concebida a partir de pressupostos inclusivos que partem da ideia de que todo aluno deve ser participante do processo educacional. Refere-se aos artigos científicos que desenvolveram ou propuseram procedimentos de ensino com diferentes perfis de alunos, ou seja, a situação didática não se restringiu apenas aos discentes com DV. A escolha do nome dessa subcategoria refere-se a ideia de Camargo (2012), na qual o aluno com DV deve ser encarado como um aluno comum do ensino regular, pois a única diferença é que estes possuem restrições (total ou parciais) para captar a informação visual do ambiente. Apesar da diferença de percepção visual existente entre alunos com e sem DV, estes artigos científicos buscaram propor atividades conjuntas entre esses alunos de forma a abranger em um mesmo contexto todos alunos simultaneamente.

Considerando que o intuito deste trabalho não é realizar análise profunda das metodologias utilizadas, mas sim deixar claro que diferentes percepções foram abordadas por meio de uma mesma proposta de trabalho (com exceção de EP14-2 e S15-3), é possível destacar que os trabalhos que fazem parte desta categoria (tabela 5), desenvolveram propostas com diferentes perfis de alunos (com e sem DV), mediante utilização de recursos de acesso multissensoriais.

Assim, os trabalhos que compõem essa categoria tiveram a finalidade de proporcionar um aprendizado para todos e todas, sem prejuízo de conteúdo para qualquer que fosse o aluno. Essas pesquisas mostram uma aproximação do discurso teórico da inclusão com a prática que efetivamente se espera dela, pois propõem oportunidades iguais de acesso a todos os alunos.

\section{Alunos com deficiência visual}

Os artigos que compõem essa subcategoria utilizaram somente uma forma de percepção não visual para a atividade didática (ou apenas o tato ou apenas a audição). Essa informação mostra que, se por um lado, houve a preocupação de evitar a dependência da visão nas atividades, considerando o aluno DV como público-alvo, por outro lado a visão muitas vezes foi "excluída" do processo. Assim, a oportunidade de compreensão de um determinado fenômeno (ou conceito) sob diferentes aspectos sensoriais 
prejudica não só o aluno com DV, que não enxerga, como pode prejudicar o vidente presente na sala de aula, ao entrar em contato com uma atividade de ensino que exclui o sentido da visão do planejamento da proposta.

Temos como exemplo o artigo S13-8, que, ao propor atividades relacionadas a termologia, estipula "No experimento o aluno deve utilizar apenas as mãos para interagir com os objetos, sem poder visualizá-los" (Oliveira, Dias \& Libardi, 2013, p. 6). Considerando esse trecho que caracteriza muito bem a proposta, é possível perceber que não houve preocupação em aproveitar estímulos visuais na configuração da atividade. Isso pode ser prejudicial para alunos videntes e também para alunos com baixa visão. E, mesmo que o aluno vidente não seja prejudicado, já que poderá usar outros sentidos para vir a aprender, a ausência de estímulos visuais não é desejável em uma atividade que preza pela inclusão, buscando opções multissensoriais para os diferentes processos de ensino e aprendizagem.

De forma contrária, temos o artigo E17-3, que propôs de modo inteligente e engenhoso uma correlação entre cores e sons, por meio das vibrações e espessuras das cordas de guitarra, fixadas em uma maquete, que simulam a refração de um raio de luz em um prisma, trabalhando assim as propriedades das ondas por meio da audição (cordas de guitarra) e do tato. É fato que, caso algum cego participe do processo, a percepção visual da cor não será possível de detectar. Todavia, a noção de cor, enquanto onda, poderá ser trabalhada de forma equivalente à que se trabalha com qualquer aluno.

Também identificamos que metade dos trabalhos que desenvolveram recursos multissensoriais, utilizaram o sentido da visão (S13-1, S13-4, S15-2 e E17-2), mas foram aplicados somente com alunos com DV, desperdiçando a oportunidade de agregarem alunos videntes em uma proposta realmente inclusiva.

De toda forma, entendemos que todos esses trabalhos tiveram como propósito prático e teórico uma busca por respostas diante do desafio de ensinar conceitos físicos para alunos com DV. São propostas originais, que buscaram contribuir para o processo de ensino de física para alunos com DV, sem deixar de mencionar aspirações futuras de que uma educação realmente inclusiva venha de fato a acontecer. 


\subsection{Participação efetiva}

Essa categoria expressa a concepção de que o educando com DV, independente do grupo em que esteja inserido, tenha envolvimento na atividade educacional proposta, ou desenvolvida, de forma atuante, explorando com objetividade e protagonismo os conceitos físicos que estão sendo ensinados ou sugeridos. O conceito chave dessa categoria aponta para a ideia de que os alunos devem ser considerados (entre suas especificidades) de forma equânime: a participação concreta em uma atividade educacional é desejável em qualquer contexto didático, independentemente se ocorre com alunos com ou sem DV (Camargo, 2012). Essa categoria, em função das características dos trabalhos investigados, também foi dividida em 2 subcategorias: Autonomia e Comunicação Interpessoal (ou Interação Social).

\section{Autonomia}

Essa subcategoria expressa a concepção de que o educando com DV tenha envolvimento na atividade educacional proposta ou desenvolvida nos artigos científicos de forma atuante, podendo explorar com objetividade e protagonismo os conceitos físicos que estão sendo ensinados ou sugeridos. Assim, considerando essa perspectiva, diante dos trabalhos investigados, essa subcategoria verificou se a atividade educacional (proposta ou aplicada) buscou estimular no estudante com DV o pensamento, a ação individual e o senso crítico, lidando com a informação transmitida de forma independente para desenvolvimento e compreensão dos conteúdos da disciplina. Nesse sentido, conforme aponta os dados organizados na tabela 5, apenas 4 artigos científicos do corpus da pesquisa não foram qualificados nesta subcategoria (S13-5, E13-1, E15-4 e E17-1), oferecendo, assim, a informação de uma preocupação constante desses trabalhos em relação à questão da autonomia.

\section{Comunicação Interpessoal (ou Interação Social)}

Essa subcategoria fundamenta-se no padrão discursivo interativo/dialógico de Camargo (2012) e expressa a ideia de que a atividade educacional deve possibilitar ao estudante com DV a troca de informações (ideias, dúvidas, questões, posicionamentos etc.) sobre os temas abordados entre seus colegas e/ou professor. Comparada com a subcategoria Autonomia (34 trabalhos classificados), conforme evidencia a tabela 5, o número de 
trabalhos nesta subcategoria é menor (22 trabalhos classificados). Não obstante, pode ter ocorrido nos trabalhos analisados uma falta de preocupação dos autores em evidenciar situações de comunicação interpessoal (ou interação social). Mas essa colocação é apenas uma hipótese, já que não é possível concluir, de acordo como as metodologias apresentadas nos trabalhos, que essa possibilidade poderia vir ser (ou não) considerada. Os quatro trabalhos anteriormente mencionados (S13-5, E13-1, E15-4 e E171), que não obtiveram classificação na subcategoria Autonomia, também não foram classificados nesta subcategoria. Isso implica uma dependência da presença da Comunicação Interpessoal (ou Interação Social) entre os participantes das propostas didáticas para que os trabalhos fossem classificados com uma participação efetiva, uma vez que a categoria é definida na coexistência das duas subcategorias.

\subsection{Recursos de acesso}

Dando continuidade ao raciocínio apresentado na categoria anterior, salientamos que a veiculação da informação não ocorre somente por meio da interação social. A acessibilidade, principalmente por parte de alunos com DV, também depende de outras formas de percepção, que podem ocorrer pela utilização de materiais específicos que permitam o processamento de informações relevantes, o que é fundamental para a efetivação do processo comunicacional. Assim, essa categoria foi configurada considerando todos os meios e recursos materiais utilizados pelo professor e pelos alunos para a organização e condução metódica do processo de ensino-aprendizagem. Neste sentido, esta categoria agrega trabalhos que se preocuparam em promover procedimentos relacionados às outras vias sensoriais (tato, audição e olfato) para que as informações possam vir a ser acessíveis aos discentes com DV.

Para a classificação das propostas, foram considerados os sentidos perceptivos presentes na elaboração da atividade. Assim, a tabela 6 classifica os trabalhos em relação à utilização de percepção sensorial, configurando-se como recursos de acesso nos trabalhos investigados. 
Tabela 6. Sentidos utilizados por meio dos recursos.

\begin{tabular}{|c|c|c|c|}
\hline Artigos científicos & Sentidos & Artigos científicos & Sentidos \\
\hline EP14-1 & audição; tato & S17-4 & tato; visão \\
\hline EP14-2 & tato & S17-5 & tato \\
\hline S13-1 & audição; tato; visão & S17-6 & tato \\
\hline S13-2 & tato & S17-7 & audição; tato; visão \\
\hline S13-3 & tato; visão & S17-8 & tato; visão \\
\hline S13-4 & tato; visão & S17-9 & audição; tato; visão \\
\hline S13-5 & tato & S17-10 & tato \\
\hline S13-6 & audição; tato & S17-11 & tato \\
\hline S13-7 & tato & E13-1 & audição; tato; visão \\
\hline S13-8 & tato & E13-2 & tato \\
\hline S13-9 & audição; tato & E13-3 & audição \\
\hline S15-1 & audição; tato; visão & E15-1 & audição; tato; visão \\
\hline S15-2 & tato; visão & E15-2 & audição; tato; visão \\
\hline S15-3 & tato & E15-3 & olfato; tato; visão \\
\hline S15-4 & audição; tato; visão & E15-4 & tato; visão \\
\hline S15-5 & tato & E17-1 & audição; visão \\
\hline S17-1 & tato; visão & E17-2 & tato; visão \\
\hline S17-2 & tato; visão & E17-3 & audição; tato \\
\hline S17-3 & tato; visão & E17-4 & tato \\
\hline
\end{tabular}

Fonte: elaborado pelos autores.

O sentido do tato, conforme tabela 8, foi o mais utilizado entre os artigos científicos, exceção feita apenas para E13-3 (audição) e E17-1 (audição e visão). Diversas maneiras foram utilizadas para explorar esse sentido, entre os mais utilizados, destacam-se alguns exemplos:

a) Material em relevo: S13-5 desenvolveu representações da reflexão, difração e interferência das ondas, assim como a experiência de Young; E13-2 elaborou um glossário de símbolos representando objetos comumente utilizados nos exercícios de Mecânica: roldanas, cordas, blocos, vetores, etc.

b) Material ampliado e miniaturizado: S13-4 desenvolveu modelos tridimensionais das cargas positivas e negativas com suas linhas de campo.

c) Texturas diferenciadas para ressaltar partes de um todo: S15-2 desenvolveu uma representação do espectro de emissão do Hidrogênio para explicar o efeito Doppler.

d) Sensações térmicas: S15-3 desenvolveu a experiência dos três baldes de Locke para discussão de conceitos relacionados a temperatura e calor;

e) Sistema braile: E15-2 desenvolveu um jogo chamado "Jogo das Usinas", que consiste em um conjunto de 12 cartões escritos em tinta e em braile (e dois dados com os números em relevo) com questões relacionadas às usinas termelétricas e hidrelétricas. 
$\mathrm{Na}$ tabela 6 verificamos que o sentido da visão (segundo lugar na classificação) esteve presente em 20 trabalhos, sendo mais utilizada com o tato (recurso tátil-visual) do que com a audição (recurso audiovisual). A audição, em terceiro lugar, esteve presente em 13 trabalhos, sendo utilizada unicamente com o tato nos artigos EP14-1, S13-6, S13-9 e E17-3, e de forma isolada no artigo E13-3. Por último, tivemos o olfato, utilizado, em conjunto com os demais sentidos (trabalho E15-3). O sentido do paladar não foi verificado em nenhum dos trabalhos. A exemplo das duas outras categorias, a categoria Recursos de Acesso foi dividida também em 2 subcategorias (Multissensoriais e Recursos Não Visuais) que serão apresentadas a seguir.

\section{Multissensoriais}

Essa subcategoria faz referência aos trabalhos que utilizaram recursos de acesso considerando a veiculação da informação por meio de diferentes sentidos. Ao nos atentarmos à tabela 6 , verificamos que alguns trabalhos analisados utilizam mais de 2 sentidos na elaboração da proposta. Nesse caso, esses trabalhos são considerados com sendo multissensoriais (estamos considerando, no mínimo, 2 sentidos sensoriais que não sejam a visão). No total, 24 artigos científicos buscaram desenvolver diferentes formas de transmissão da informação, considerando aspectos multissensoriais. Recursos multissensoriais são capazes de unificar experiências, abrindo canais de comunicação entre alunos com e sem DV, e contribuindo para que discussões acerca do fenômeno estudado se tornem mais proveitosas, aumentando a possibilidade de Comunicação Interpessoal (Anjos, 2011; Camargo, 2008, 2011).

\section{Não visuais}

Essa subcategoria faz referência aos trabalhos que utilizaram recursos de acesso considerando a veiculação da informação apenas por um estímulo não visual. Dos 14 trabalhos classificados nesta subcategoria, 13 utilizaram o sentido do tato e somente 1 o sentido da audição (E13-3) como forma de transmissão da informação (tabela 6).

Algo que sempre é importante lembrar consiste no fato de que o discente com DV possui, geralmente, os outros sentidos inalterados como qualquer pessoa. Apesar da capacidade de obtenção e processamento da informação pelo tato, essa não é a única maneira de construção do conhecimento (diversos fenômenos estudados na física corroboram essa afirmação). Dessa 
forma, propostas de atividades educacionais que utilizam apenas o tato (ou apenas um sentido) poderiam ser mais bem aproveitadas se planejadas com a utilização, em conjunto, de outros canais sensoriais.

\section{Discussão dos resultados: a busca por trabalhos inclusivos}

Diante os argumentos expostos nas análises e discussões das categorias/ subcategorias, considera-se, portanto, verdadeiramente inclusivo, o artigo científico classificado simultaneamente nas subcategorias: Alunos são apenas alunos (C1.1), Autonomia (C2.1), Interação social/Comunicação interpessoal (C2.2) e Multissensoriais (C3.1). Cada uma dessas subcategorias atua como uma diretriz da educação inclusiva. A presença de forma concomitante de todas essas características em um mesmo projeto ou atividade proporciona, de fato, uma educação inclusiva legítima. Nesse sentido, a tabela 7 apresenta a classificação das atividades como inclusivas, ou não.

Tabela 7. Análise de conteúdo: buscando trabalhos inclusivos

\begin{tabular}{|c|c|c|c|c|c|c|c|c|}
\hline \multirow[t]{2}{*}{ Evento } & \multirow[t]{2}{*}{$N$} & \multicolumn{2}{|c|}{$\mathrm{C} 1$} & \multicolumn{2}{|c|}{$\mathrm{C} 2$} & \multicolumn{2}{|c|}{ C3 } & \multirow[t]{2}{*}{ Resultado } \\
\hline & & C1.1 & C1.2 & C2.1 & $\mathrm{C} 2.2$ & C3.1 & C3.2 & \\
\hline \multirow{2}{*}{$\begin{array}{l}\text { EPEF } \\
2014\end{array}$} & EP14-1 & & $x$ & $x$ & $x$ & $x$ & & Não inclusivo \\
\hline & EP14-2 & $x$ & & $x$ & $x$ & & $x$ & Não inclusivo \\
\hline \multirow{9}{*}{$\begin{array}{l}\text { SNEF } \\
2013\end{array}$} & S13-1 & & $x$ & $x$ & & $x$ & & Não inclusivo \\
\hline & S13-2 & & $x$ & $x$ & & & $x$ & Não inclusivo \\
\hline & S13-3 & $x$ & & $x$ & & $x$ & & Não inclusivo \\
\hline & S13-4 & & $x$ & $x$ & $x$ & $x$ & & Não inclusivo \\
\hline & S13-5 & & $x$ & & & & $x$ & Não inclusivo \\
\hline & S13-6 & & $x$ & $\mathrm{x}$ & $x$ & $\mathrm{X}$ & & Não inclusivo \\
\hline & S13-7 & & $x$ & $x$ & $x$ & & $x$ & Não inclusivo \\
\hline & S13-8 & & $x$ & $x$ & $x$ & & $x$ & Não inclusivo \\
\hline & S13-9 & & $x$ & $x$ & & $x$ & & Não inclusivo \\
\hline \multirow{5}{*}{$\begin{array}{l}\text { SNEF } \\
2015\end{array}$} & S15-1 & $x$ & & $x$ & $x$ & $x$ & & Inclusivo \\
\hline & S15-2 & & $\mathrm{x}$ & $x$ & & $x$ & & Não inclusivo \\
\hline & S15-3 & $x$ & & $x$ & $x$ & & $x$ & Não inclusivo \\
\hline & S15-4 & $x$ & & $x$ & $x$ & $x$ & & Inclusivo \\
\hline & S15-5 & & $x$ & $x$ & $x$ & & $\mathrm{X}$ & Não inclusivo \\
\hline
\end{tabular}




\begin{tabular}{|c|c|c|c|c|c|c|c|c|}
\hline \multirow[t]{2}{*}{ Evento } & \multirow[t]{2}{*}{$\mathrm{N}$} & \multicolumn{2}{|c|}{$\mathrm{C} 1$} & \multicolumn{2}{|c|}{$\mathrm{C} 2$} & \multicolumn{2}{|c|}{ C3 } & \multirow[t]{2}{*}{ Resultado } \\
\hline & & C1.1 & C1.2 & C2.1 & $\mathrm{C} 2.2$ & C3.1 & C3.2 & \\
\hline \multirow{11}{*}{$\begin{array}{l}\text { SNEF } \\
2017\end{array}$} & S17-1 & $x$ & & $x$ & $x$ & $x$ & & Inclusivo \\
\hline & S17-2 & $x$ & & $x$ & & $x$ & & Não inclusivo \\
\hline & S17-3 & $x$ & & $x$ & & $x$ & & Não inclusivo \\
\hline & S17-4 & $\mathrm{X}$ & & $x$ & & $\mathrm{X}$ & & Não inclusivo \\
\hline & S17-5 & & $\mathrm{X}$ & $x$ & $x$ & & $X$ & Não inclusivo \\
\hline & S17-6 & & $x$ & $x$ & $x$ & & $\mathrm{x}$ & Não inclusivo \\
\hline & S17-7 & $x$ & & $x$ & $x$ & $x$ & & Inclusivo \\
\hline & S17-8 & $x$ & & $x$ & $x$ & $x$ & & Inclusivo \\
\hline & S17-9 & $x$ & & $x$ & $x$ & $x$ & & Inclusivo \\
\hline & S17-10 & & $x$ & $x$ & & & $x$ & Não inclusivo \\
\hline & S17-11 & & $x$ & $x$ & & & $x$ & Não inclusivo \\
\hline \multirow{3}{*}{$\begin{array}{l}\text { ENPEC } \\
2013\end{array}$} & E13-1 & $x$ & & . & & $x$ & & Não inclusivo \\
\hline & E13-2 & & $x$ & $x$ & $x$ & & $x$ & Não inclusivo \\
\hline & E13-3 & & $x$ & $x$ & & & $x$ & Não inclusivo \\
\hline \multirow{4}{*}{$\begin{array}{l}\text { ENPEC } \\
2015\end{array}$} & E15-1 & $x$ & & $x$ & $x$ & $x$ & & Inclusivo \\
\hline & E15-2 & $x$ & & $x$ & $x$ & $x$ & & Inclusivo \\
\hline & E15-3 & $x$ & & $x$ & $x$ & $x$ & & Inclusivo \\
\hline & E15-4 & $x$ & & & & $x$ & & Não inclusivo \\
\hline \multirow{4}{*}{$\begin{array}{l}\text { ENPEC } \\
2017\end{array}$} & E17-1 & $x$ & & & & $x$ & & Não inclusivo \\
\hline & $\mathrm{E} 17-2$ & & $x$ & $x$ & $x$ & $x$ & & Não inclusivo \\
\hline & E17-3 & & $x$ & $x$ & $x$ & $x$ & & Não inclusivo \\
\hline & E17-4 & & $x$ & $x$ & & & $x$ & Não inclusivo \\
\hline
\end{tabular}

Fonte: elaborado pelos autores.

Com essa análise, apenas 9 artigos científicos apresentados entre os anos 2013-2017, em eventos científicos nacionais de Ensino de Física e de Ensino de Ciências, estão de acordo com uma proposta verdadeiramente inclusiva. Contudo, cabe apontar que, associar trabalhos a uma educação efetivamente inclusiva somente porque de alguma forma se posicionam favoráveis à mesma, é incorreto. Antes é preciso averiguar adequadamente a proposta apresentada (ou desenvolvida). Por fim, a tabela 8 sintetiza os resultados por evento para o período considerado para a pesquisa (2013-2017). 
Tabela 8. Número de trabalhos analisados e inclusivos.

\begin{tabular}{lccccccccc}
\hline \multicolumn{1}{c}{ Evento } & \multicolumn{2}{c}{ EPEF } & \multicolumn{3}{c}{ SNEF } & \multicolumn{3}{c}{ ENPEC } \\
& 2014 & 2016 & 2013 & 2015 & 2017 & 2013 & 2015 & 2017 \\
Ano & 2 & 0 & 9 & 5 & 11 & 3 & 4 & 4 \\
No de trabalhos analisados $^{*}$ No de trabalhos inclusivos $^{0}$ & 0 & 0 & 0 & 2 & 4 & 0 & 3 & 0 \\
\hline
\end{tabular}

Fonte: elaborado pelos autores.

Com essas colocações, é possível apontar que o estudo forneceu um ponto de partida para averiguar, a partir de uma perspectiva inclusiva, como propostas de ensino de física têm sido desenvolvidas (e/ou aplicadas) para pessoas com DV. Considerando a amplitude e a riqueza dos aspectos envolvidos, nota-se que os textos dos artigos científicos analisados disponibilizaram dados suficientes para revelar a conjuntura da inclusão, à medida em que as categorias/subcategorias elaboradas forneceram diretrizes pertinentes para essa apreciação.

\section{Considerações finais}

O desenvolvimento do presente estudo possibilitou uma análise dos artigos científicos, apresentados nos últimos cinco anos (2013-2017) nos eventos científicos nacionais de Ensino de Física (EPEF e SNEF) e de Ensino de Ciências (ENPEC), que tratam sobre o ensino de Física para pessoas com deficiência visual, pautados, do ponto de vista didático, no ensino e aprendizagem, em perspectiva da educação inclusiva. Os resultados indicaram um valor muito abaixo do esperado, em comparação à quantidade de trabalhos analisados: dos 38 artigos científicos, apenas 9 apresentaram-se condizentes com uma educação verdadeiramente inclusiva.

É importante esclarecer que esta pesquisa não buscou desqualificar nenhum dos artigos científicos apresentados nos eventos, pois o comprometimento dos autores perante um assunto tão relevante e incipiente já mostra intrinsicamente o seu notável valor, sendo justamente a divulgação desses trabalhos uma forma gradativa de alcançar a educação inclusiva. Contudo, procurou-se revelar o que pode ser aperfeiçoado, revitalizado, ajustado e corrigido para fortalecer a escolarização de todos os alunos, sejam eles com ou sem deficiência visual. 
Nesse sentido, o tratamento dos dados realizado por meio da Análise de Conteúdo propiciou a reunião de elementos significativos com as mesmas características, que, sob um título conceitual, forneceram distintas categorizações, as quais se consolidam, neste estudo, como diretrizes para uma educação inclusiva, tomadas a partir do referencial teórico desenvolvido. Essa análise, mediada de forma conjunta pelos objetivos específicos, não apenas possibilitou ampliar a compreensão do tema abordado, como também responder ao problema incialmente proposto, mediante a identificação dos trabalhos que estão de acordo com uma educação verdadeiramente inclusiva, objetivo geral do estudo.

Tendo em vista que a presente investigação se baseou em uma forma particular de interpretar os dados, é importante elucidar que o assunto não se esgotou. O que aqui foi apontado não é um estudo que fecha em si mesmo. Outras observações e hipóteses podem ser levantadas e utilizadas para trazer novas informações e gerar distintas perspectivas.

Por fim, com este trabalho espera-se que estudantes de licenciatura, professores da educação básica e pesquisadores da área de Ensino de Física despertem para a necessidade de mudanças em suas práticas de ensino de modo a desenvolverem uma aula legitimamente inclusiva. Espera-se contribuir para a reflexão e a realização de práticas que contem com a participação de alunos com e sem DV, planejadas e conduzidas de forma participativa e adequada às múltiplas formas de percepção sensorial dos alunos e dos fenômenos físicos.

\section{Referências}

Amaral, L.A. (2002). Diferenças, estigma e preconceito: o desafio da inclusão. In: M. K. de Oliveira, T. C. Rego, D. Tr. R. Souza (orgs.). Psicologia, educação e as temáticas da vida contemporânea. São Paulo: Moderna, 233-248.

Andrés, A. (2014). Pessoas com deficiência nos censos populacionais e educação inclusiva. Brasília: Câmara dos Deputados. Disponível em https://bit.ly/3I0c83k.

Anjos, P. T. A.; Camargo, E. P. (2011). Didática multissensorial e o ensino inclusivo de ciências. Revista de la Facultad de Ciencia y Tecnologia, 17(especial), 192-196.

Bardin, L. (2011). Análise de conteúdo. Tradução de Luís Antero Reto e Augusto Pinheiro. São Paulo: Edições 70.

Brasil (1988). Constituição. Constituição da República Federativa do Brasil. Brasília, DF: Senado. 
Brasil (1996). Lei 9.394, de 20 de dezembro de 1996. Estabelece as diretrizes e bases da educação nacional. Brasília.

Brasil (2002). Ministério da Educação. Portaria nº 2.678 de 24 de Setembro de 2002. Disponível em https://bit.ly/3ehQ8iY.

Brasil (2004). Casa Civil. Decreto $n^{0} 5.296$ de 2 de Dezembro de 2004. Estabelece normas gerais e critérios básicos para a promoção da acessibilidade das pessoas portadoras de deficiência ou com mobilidade reduzida, e dá outras providências. Disponível em https://bit.ly/38IXWfA.

Brasil (2018). Ministério da Educação (MEC). Censo Escolar 2017: Notas Estatísticas. Brasília: Instituto Nacional de Estudos e Pesquisas Educacionais Anísio Teixeira (Inep). Disponível em https://bit.ly/3bsFcgt.

Camargo, E.P. (2008). Ensino de Física e deficiência visual: dez anos de investigações no Brasil. São Paulo: Plêiade / FAPESP.

Camargo, E.P. (2012). Saberes docentes para a inclusão do aluno com deficiência visual em aulas de Física. São Paulo: Editora Unesp.

Camargo, E.P. (2016a). Inclusão, multissensorialidade, percepção e linguagem. In: CAMARGO, E.P. Inclusão e necessidade especial: compreendendo identidade e diferença por meio do ensino de física e da deficiência visual. São Paulo: Editora Livraria da Física.

Camargo, E.P. (2016b). Saberes docentes mobilizados nos contextos da formação em licenciatura em física e dos estudantes com e sem deficiência visual. Tese (livre-docência) Universidade Estadual Paulista Júlio de Mesquita Filho, Faculdade de Engenharia de Ilha Solteira. Disponível em http://bit.ly/30qZzUZ

Camargo, E.P., Nardi, R. \& Correia, J.N. (2010). A comunicação como barreira à inclusão de alunos com deficiência visual em aulas de Física Moderna. Revista Brasileira de Pesquisa em Educação em Ciências, 10(2), 1-18.

Carvalho, A.M.P. \& GIL-Pérez, D. (2011). Formação de professores de Ciências: tendências e inovações. São Paulo: Cortez.

Carvalho, A.M.P. \& Sasseron, L.H. (2018). Ensino e aprendizagem de Física no Ensino Médio e a formação de professores. Estudos Avançados, 32(94), 43-55.

Gil, A. C. (2017). Como elaborar projetos de pesquisa. 6. ed. São Paulo: Atlas.

Gil-Pérez, D. \& Vilches, A. (2005). Importância da Educação Científica na Sociedade Actual. In: A. Cachapuz, D. Gil-Perez, A.M.P. Carvalho, J. Praia \& A. Vilches (2005). ANecessária renovação do ensino das ciências, pp. 19-34 São Paulo: Cortezm.

Marconi, M.A \& Lakatos, E.M. (2017). Fundamentos de Metodologia Científica. 8. ed. São Paulo: Atlas.

Mendes, E.G. (2006). A radicalização do debate sobre inclusão escolar no Brasil. Revista Brasileira de Educação, 11(33), 387-405.

Nuernberg, A.H. (2008). Contribuições de Vigotski para a educação de pessoas com deficiência visual. Psicologia em estudo, 13(2), 307-316.

Oliveira, L. M. B. (2012). Cartilha do Censo 2010: Pessoas com Deficiência. Brasília: Secretaria de Direitos Humanos da Presidência da República (SDH/PR) / Secretaria Nacional de Promoção dos Direitos da Pessoa com Deficiência (SNPD) / Coordenação-Geral 
do Sistema de Informações sobre a Pessoa com Deficiência. Disponível em https:// bit.ly/3sYMTky.

Oliveira, G.A., Dias, E.M.C. \& Libardi, H. (2013). O ensino da física para a educação inclusiva: relato de um experimento com deficiente visual. In: Atas do Simpósio Nacional de Ensino de Física 2013. São Paulo: Sociedade Brasileira de Física. Disponível em https://bit.ly/2OAINBX.

Omote, S. (1986). A deficiência como fenômeno socialmente construído. UNESP. Marília.

Richardson, R.J., Peres, J.A.S., Wanderley, J.C.V., Correia, L.M., Peres, M.H.M. (2012). Pesquisa social: métodos e técnicas. São Paulo: Atlas

Torres, E. F.; Mazzoni, A. A.; Mello, A. G. (2007). Nem toda pessoa cega lê em Braille nem toda pessoa surda se comunica em língua de sinais. Educação e Pesquisa, 33(2), 369-385.

Veraszto, E.V., Camargo, E.P, Camargo, J.T.F., Simon, F.O. \& Miranda, N.A. (2018a). Evaluation of concepts regarding the construction of scientific knowledge by the congenitally blind: an approach using the Correspondence Analysis method. Ciência \& Educação, 24, 837-857.

Veraszto, E. V., Camargo, E. P., Camargo, J. T. F., Simon, F. O., Yamaguti, M. X. \& Souza, A. M.M. (2018b). Conceitualização em ciências por cegos congênitos: um estudo com professores e alunos do ensino médio regular. Revista Electrónica de Enseñanza de las Ciencias,17, 540-563.

Vigotski, L.S. (1997). Obras Escogidas: V Fundamentos de Defectología. Editora Aprendizaje Visor: Madrid.

Yamazaki, S.C., Angotti, J.A.P. \& Delizoicov, D. (2017). Aprender como Ensinar Física através do Livro Texto de Ciclo Básico Universitário: um Fenômeno Didático em questão. Amazônia - Revista de Educação em Ciências e Matemática,13(28),5-22.

Zatti, V. (2007). Autonomia e educação em Immanuel Kante Paulo Freire. Porto Alegre: EDIPUCRS Disponível em https://bit.ly/30vbelD. 